\title{
Determination of Downy Mildew and Powdery Mildew Resistance of Some Grape Cultivars
}

\author{
A. Atak \\ Department of Viticulture, Ataturk Horticulture Central Research Institute, Yalova, Turkey
}

Submitted for publication: June 2016

Accepted for publication: October 2016

Key words: Vitis spp., disease severity, resistance, inoculation, natural infection

\begin{abstract}
Different grape cultivars of Vitis species have been cultivated in Turkey since ancient times. A large proportion of these cultivars cannot be cultivated in the humid regions of the country due to downy mildew (Plasmopara viticola) and powdery mildew (Uncinula necator or syn. Erysiphe necator) diseases. Cultivars resistant to these diseases can generally grow without any or fewer fungicide applications. However, there are also differences in the resistance level of cultivars. In particular, Vitis vinifera cultivars, the most widely cultured species, are most affected by these diseases. Thirteen $V$. vinifera cultivars, eight $V$. labrusca cultivars and six interspecific cultivars were used in this study, for a total of 27 cultivars. The resistance of cultivars against downy mildew and powdery mildew was determined over two years with natural infection and artificial inoculation applications. Generally, all cultivars showed more resistance to downy mildew, while they also showed lower resistance to powdery mildew. The evaluation based on species found $V$. vinifera to be the most sensitive. While interspecific cultivars were found to be most resistant to downy mildew, $V$. labrusca cultivars were the most resistant to powdery mildew. Among cultivars of the same species, however, differences in terms of resistance were observed. These differences can be used in breeding studies in order to obtain new, disease-resistant cultivars, which may be grown commercially to comply with good agricultural practices (GAP) or organic viticulture in the future.
\end{abstract}

\section{INTRODUCTION}

Turkey has a very ancient history of viticulture and it is still an important agricultural sector. Mainly $V$. vinifera cultivars are grown and they are used mostly for the purposes of fresh consumption, and raisin and wine production. However, a large proportion of these cultivars are quite susceptible to downy mildew and powdery mildew. Therefore, spraying is done around 10 to 15 times annually to ensure quality production. This situation raises many risks for human health and the environment. In particular, the increasing demand for organic agricultural products and good agricultural practices has increased interest in disease-resistant varieties. Breeding strategies include the development of new cultivars that need less spraying and produce better quality grapes (Eibach \& Töpfer, 2014; Rex et al., 2014). Previous studies were focused mainly on wine grapes, but there are a few studies on table grapes (Kozma et al., 2014). V. labrusca cultivars are grown in the northern part of Turkey, especially along the Black Sea coastline. The cultivars that are grown in Turkey are usually resistant to or tolerant of downy mildew and powdery mildew (Çelik et al., 2008; Gessler et al., 2011). This species was brought from Russia to Turkey and then spread throughout the Black Sea region. Some cultivars grown in the Black Sea region originated from $V$. vinifera crossed with $V$. labrusca. These hybrid genotypes vary in resistance to fungal diseases (Bailey, 1934; Cahoon, 1986; Mullins et al., 1992) and the level of resistance must be determined by natural and artificial inoculation in order to select disease-resistant cultivars. Studies in natural conditions without artificial inoculation do not produce realistic results regarding the resistance level of genotypes.

Different studies have been carried out to determine the resistance level of genotypes to various diseases and to identify resistant genotypes for use in breeding studies (Kozma, 1998; Özer et al., 2012; Merdinoglu et al., 2014). Recent developments in biotechnology, and especially in the development of genetic markers associated with disease resistance, have been implemented in breeding studies. Therefore, new resistant genotypes can be obtained in a shorter time with more accurate results compared to conventional methods for resistance-breeding studies (Eibach \& Töpfer, 2014; Reisch et al., 2014).

In this study, the downy and powdery mildew resistance levels of a total of 27 cultivars were determined by using natural infection and artificial inoculation. The most resistant 
cultivars were identified and can be used as resistant donors in later breeding programmes.

\section{MATERIAL AND METHODS \\ Plant material}

Twenty-seven different grape cultivars that are grown in the Yalova Atatürk Horticultural Central Research Institute vineyards were used in this study (Table 1). Eight V. labrusca cultivars, considered to be resistant to fungal diseases, were collected from the north of Turkey, especially around the Black Sea coastline. In addition to the V. labrusca cultivars, the study included six interspecific cultivars that may be considered resistant in terms of downy and powdery mildew. Finally, 13 different $V$. vinifera cultivars were used for comparison.

\section{Preparation of inoculum and inoculation of plants Natural infection}

The experiments were carried out according to standard viticultural practices and no pesticides or fungicides were used in the experimental areas for two years. All vines were potted (minimum three plants per cultivar with three replicates) and exposed to natural infection. Different plants were used for powdery and downy mildew natural infection and disease scoring. Infected leaves and shoots were distributed randomly amongst the trial plants in order to provide sufficient inoculation. The evaluation of natural infection was carried out on leaves and clusters during July and August.

\section{Artificial inoculation}

All vines were planted in pots and cultivated in the greenhouse for powdery and downy mildew inoculation. There were a minimum of three plants per cultivar with three replicates. Different plants were used for powdery and downy mildew artificial inoculation. For the artificial inoculation of plants with powdery mildew, the modified method of Wang et al. (1995) was used. Conidia were collected from infected leaves, washed with $78 \%$ glucose solution to imitate the osmotic pressure of powdery mildew conidia, and then suspended in sterile water. Vine leaves were inoculated with the conidial suspension at a rate of $2 \times 10^{5}$ conidia $/ \mathrm{mL}$ by spraying the upper surface of the leaves. Inoculated leaves were immediately covered with thin plastic for six hours

The methods of Rumbolz et al. (2002) and Boso et al. (2006) were used to propagate sporangia inoculum for downy mildew inoculation. P. viticola was obtained from naturally infected plants in the vineyards of the Atatürk Horticulture Central Research Institute, Yalova, Turkey and the Çukurova University Agriculture Faculty, Adana, Turkey. For the propagation of the inoculum, plants were sprayed with a suspension of sporangia (40 000 sporangia/ $\mathrm{mL}$ distilled water) on the abaxial leaf side and the whole plant was covered with a polyethylene cover overnight. On the following day, the polyethylene covers were removed and incubation lasted five to six days at $25^{\circ} \mathrm{C}$. The trial plants were inoculated by repeating the procedure after one week.

\section{Evaluation of disease symptoms}

For the evaluation of powdery mildew, four young leaves (first, second, third and fourth leaf from shoot tip) were selected from each vine and were examined at different times from June to August. The infection severity on the leaves was determined on the basis of the percentage of disease spots observed on the entire leaf area according to the procedure described in Table 1 (GENRES-081, 1997). Disease severity was scored three weeks after inoculation.

For the evaluation of downy mildew, all the leaves of each plant were evaluated at different times from May to August. The infection severity on the leaves was determined

TABLE 1

Rating levels for powdery mildew infection of leaves of genotypes for their degree of resistance under the same conditions.

\begin{tabular}{cl}
\hline Level & Symptoms \\
\hline 1 & Very low (tiny spots or no symptoms; neither visible sporulation nor mycelium) \\
3 & $\begin{array}{l}\text { Low (limited patches }<2 \mathrm{~cm} \text { diameter; limited sporulation and mycelium; the presence of Uncinula is only } \\
\text { indicated by a slight curling of the blade) }\end{array}$ \\
5 & Medium (patches usually limited to a diameter of 2 to $5 \mathrm{~cm}$ ) \\
7 & High (vast patches; some limited; strong sporulation and abundant mycelium) \\
9 & Very high (very vast, unlimited patches or totally attached leaf blades; strong sporulation and abundant mycelium) \\
\hline
\end{tabular}

TABLE 2

Rating levels for infection of leaves of genotypes for their degree of resistance to downy mildew under the same conditions.

\begin{tabular}{cl}
\hline Level & Symptoms \\
\hline 1 & Very low (tiny necrotic spots or no symptoms; neither sporulation nor mycelium) \\
3 & Low (small patches $<1 \mathrm{~cm}$ in diameter; little sporulation or mycelium) \\
5 & Medium (little patches 1 to $2 \mathrm{~cm}$ in diameter; more or less strong sporulation; irregular formation of mycelium) \\
7 & High (vast patches; strong sporulation and abundant mycelium; leaf drop later than below) \\
9 & Very high (vast patches or totally attached leaf blades; strong sporulation and dense mycelium; very early leaf \\
& drop) \\
\hline
\end{tabular}


on the basis of the percentage of disease spots observed on the entire leaf area according to the procedure described in Table 2 (GENRES-081, 1997). Scoring was done six weeks after inoculation.

\section{Disease assessment and statistical analysis}

Scoring was done primarily to determine the response of plants to the two pathogens causing downy and powdery mildew during the two growing seasons (Tables 3 and 4). Disease severity was estimated as the percentage of affected leaves. Disease severity (infection degree, ID) was computed using a scale of total number of classes with the TownsendHeuberger formula (Townsend \& Heuberger, 1943): ID (\%) $=\Sigma \mathrm{i} 1(n i \times v i) / N \times V$, where $v i$ is the damage class, $n i$ is the number in one class, $N$ is the total number, $V$ is the highest class, and $\mathrm{i}$ is the number of classes.
The resistance level of each cultivar to downy mildew was rated based on its disease severity index (SI) (Boso et al., 2006):

ER - Extremely resistant, SI: 0 to 5.0

HR - Highly resistant, SI: 5.1 to 25

$\mathrm{R}$ - Resistant, SI: 25.1 to 50

S - Susceptible, SI: 50.1 to 75

HS - Highly susceptible, SI: > 75.1

The resistance level of each cultivar to powdery mildew was rated based on its severity index (SI) (Wang et al., 1995): ER - Extremely resistant, SI: 0

HR - Highly resistant, SI: 0.1 to 5.0

R - Resistant, SI: 5.1 to 25.0

S - Susceptible, SI: 25.1 to 50

HS - Highly susceptible, SI: $=50.1$ to 100

TABLE 3

Disease severity of accessions for downy mildew

\begin{tabular}{|c|c|c|c|c|c|}
\hline \multirow[t]{2}{*}{ Cultivars } & \multirow[t]{2}{*}{ Species } & \multicolumn{2}{|c|}{ Natural infection } & \multicolumn{2}{|c|}{ Inoculation } \\
\hline & & Average $^{\mathrm{ab}}(\%)$ & Severity Index & Average $^{\mathrm{ab}}(\%)$ & Severity Index \\
\hline Erenköy Beyazı klon 27 & V. vinifera & $6,7^{\mathrm{cd}}$ & HR & $45,3^{b-d}$ & $\overline{\mathrm{R}}$ \\
\hline Bilecik İri Karası klon 107 & $V$. vinifera & $4,3^{\mathrm{cd}}$ & ER & $28,7^{\mathrm{f}}$ & $\mathrm{R}$ \\
\hline Ribol & V. vinifera & $11,0^{b-d}$ & HR & $32,7^{\text {ef }}$ & $\mathrm{R}$ \\
\hline Lival & $V$. vinifera & $7,0^{\mathrm{cd}}$ & HR & $46,7 \mathrm{bc}$ & $\mathrm{R}$ \\
\hline $86 / 1$ & $V$. vinifera & $6,3^{\mathrm{cd}}$ & HR & $37,3^{\mathrm{d}-\mathrm{f}}$ & $\mathrm{R}$ \\
\hline Atak 77 & V. vinifera & $24,7^{\mathrm{bc}}$ & HR & $43,6^{b-d}$ & $\mathrm{R}$ \\
\hline Pembe 77 & V. vinifera & $13,3^{b-d}$ & HR & $50,0^{\mathrm{b}}$ & $\mathrm{R}$ \\
\hline Arifbey & $V$. vinifera & $20,0^{b-d}$ & HR & $32,0^{\text {ef }}$ & $\mathrm{R}$ \\
\hline Kömüşmemesi & $V$. vinifera & $68,0^{\mathrm{a}}$ & $\mathrm{S}$ & $66,0^{\text {a }}$ & $\mathrm{S}$ \\
\hline Pembe üzüm & $V$. vinifera & $52,7^{\mathrm{a}}$ & $\mathrm{S}$ & $48,7 \mathrm{bc}$ & $\mathrm{R}$ \\
\hline Akdimrit & $V$. vinifera & $64,3^{\text {a }}$ & $\mathrm{S}$ & $50,7^{\mathrm{b}}$ & $\mathrm{S}$ \\
\hline Antep büzgülü & $V$. vinifera & $54,3^{a}$ & $\mathrm{~S}$ & $49,7^{b}$ & $\mathrm{R}$ \\
\hline Italia & V. vinifera & $20,3^{b-d}$ & HR & $40,3^{\mathrm{c}-\mathrm{e}}$ & $\mathrm{R}$ \\
\hline 55 Merkez 11 & V. labrusca & $3,6^{\mathrm{d}}$ & ER & $43,0^{\mathrm{b}-\mathrm{d}}$ & $\mathrm{R}$ \\
\hline 53 Güneysu 02 & V. labrusca & $0^{d}$ & ER & $1,3^{\mathrm{jk}}$ & ER \\
\hline Giresun T-1 & V. labrusca & $10,3^{\mathrm{cd}}$ & HR & $16,0^{\mathrm{g}}$ & HR \\
\hline Giresun T-3 & V. labrusca & $4,7^{\mathrm{cd}}$ & ER & $10,3^{\mathrm{g}-\mathrm{i}}$ & HR \\
\hline Giresun T-5 & V. labrusca & $9,0^{\mathrm{cd}}$ & HR & $10,7^{\mathrm{g}-\mathrm{i}}$ & HR \\
\hline Sinop T-1 & V. labrusca & $31,7^{\mathrm{b}}$ & $\mathrm{R}$ & $13,0^{\mathrm{gh}}$ & HR \\
\hline Sinop T-3 & V. labrusca & $16,3^{\mathrm{b}-\mathrm{d}}$ & HR & $8,7^{\mathrm{g}-\mathrm{k}}$ & HR \\
\hline Köfteci üzümü & V. labrusca & $1,0^{\mathrm{d}}$ & ER & $5,0^{\mathrm{h}-\mathrm{k}}$ & ER \\
\hline Mortensen & Interspecific cross & $0^{d}$ & ER & $9,7^{\mathrm{g-j}}$ & HR \\
\hline Alden & Interspecific cross & $2,3^{d}$ & ER & $3,0^{\mathrm{i}-\mathrm{k}}$ & ER \\
\hline Kay Grey & Interspecific cross & $0^{\mathrm{d}}$ & ER & $4,3^{h-k}$ & ER \\
\hline Seneca & Interspecific cross & $3,0^{d}$ & ER & $5,7^{\mathrm{h}-\mathrm{k}}$ & HR \\
\hline Canadice & Interspecific cross & $0^{\mathrm{d}}$ & ER & $3,7^{\mathrm{i}-\mathrm{k}}$ & ER \\
\hline Lakemont & Interspecific cross & $8,0^{\mathrm{cd}}$ & HR & $0^{\mathrm{k}}$ & ER \\
\hline
\end{tabular}

a Average severity of downy mildew across all replicates was rated in 2014 and 2015 for each accession.

${ }^{\mathrm{b}}$ Data followed by the same letter in each column do not differ significantly ( $\mathrm{p} \leq 0.05$ ) according to Duncan's multiple range test. (ER, Extremely resistant; HR, Highly resistant; R, Resistant; S, Susceptible; HS, Highly susceptible) 
TABLE 4

Disease severity of accessions for powdery mildew

\begin{tabular}{|c|c|c|c|c|c|}
\hline \multirow{2}{*}{ Cultivars } & \multirow{2}{*}{ Species } & \multicolumn{2}{|c|}{ Natural infection } & \multicolumn{2}{|c|}{ Inoculation } \\
\hline & & Severity Index & Average $^{\mathrm{ab}}(\%)$ & Severity Index & Average $^{\mathrm{ab}}(\%)$ \\
\hline Erenköy Beyazı klon 29 & V. vinifera & $1,3^{\mathrm{i}}$ & HR & $40,3^{\mathrm{e}-\mathrm{g}}$ & $\mathrm{S}$ \\
\hline Bilecik İri Karası klon 107 & V. vinifera & $9,7^{\mathrm{g}-\mathrm{i}}$ & $\mathrm{R}$ & $25,0^{f-j}$ & $\mathrm{R}$ \\
\hline Ribol & V. vinifera & 32,3 de & $\mathrm{S}$ & $66,7 \mathrm{bc}$ & HS \\
\hline Lival & V. vinifera & $5,0^{\mathrm{i}}$ & HR & $18,0^{\mathrm{h}-\mathrm{k}}$ & $\mathrm{R}$ \\
\hline $86 / 1$ & V. vinifera & $26,3^{\mathrm{e}-\mathrm{g}}$ & $\mathrm{S}$ & $25,0^{f-j}$ & $\mathrm{R}$ \\
\hline Atak 77 & V. vinifera & 27,3 ef & S & $27,7^{\mathrm{f}-\mathrm{i}}$ & $\mathrm{S}$ \\
\hline Pembe 77 & V. vinifera & $26,0^{\mathrm{e}-\mathrm{g}}$ & $\mathrm{S}$ & $51,3^{\mathrm{c}-\mathrm{e}}$ & HS \\
\hline Arifbey & V. vinifera & $24,0^{e-i}$ & $\mathrm{R}$ & $40,7^{\text {e-g }}$ & $\mathrm{S}$ \\
\hline Kömüşmemesi & V. vinifera & $0^{\mathrm{i}}$ & ER & $12,0^{\mathrm{i}-\mathrm{k}}$ & $\mathrm{R}$ \\
\hline Pembe üzüm & V. vinifera & $75,0^{\text {a }}$ & HS & $90,3^{\text {a }}$ & HS \\
\hline Akdimrit & V. vinifera & $72,7^{\mathrm{ab}}$ & HS & $84,3^{\mathrm{ab}}$ & HS \\
\hline Antep Büzgülü & V. vinifera & $64,0^{\mathrm{a}-\mathrm{c}}$ & HS & $89,0^{\mathrm{ab}}$ & HS \\
\hline Italia & V. vinifera & $64,0^{a-c}$ & HS & $64,0^{\mathrm{b}-\mathrm{d}}$ & HS \\
\hline 55 Merkez 11 & V. labrusca & 7,0 hi & $\mathrm{R}$ & $4,0^{\mathrm{jk}}$ & HR \\
\hline 53 Güneysu 02 & V. labrusca & $25,0^{\mathrm{e}-\mathrm{g}}$ & $\mathrm{R}$ & $46,7^{\mathrm{d}-\mathrm{f}}$ & $\mathrm{S}$ \\
\hline Giresun T-1 & V. labrusca & $7,3 \mathrm{hi}$ & $\mathrm{R}$ & $0^{\mathrm{k}}$ & ER \\
\hline Giresun T-3 & V. labrusca & 32,3 de & $\mathrm{S}$ & $33,3^{e-i}$ & $\mathrm{~S}$ \\
\hline Giresun T-5 & V. labrusca & $4,7^{\mathrm{i}}$ & HR & $3,7^{\mathrm{jk}}$ & $\mathrm{HR}$ \\
\hline Sinop T-1 & V. labrusca & $12,0^{\mathrm{f}-\mathrm{i}}$ & $\mathrm{R}$ & $29,7^{\mathrm{f}-\mathrm{i}}$ & $\mathrm{S}$ \\
\hline Sinop T-3 & V. labrusca & 34,3 de & $\mathrm{S}$ & $36,0^{\mathrm{e}-\mathrm{h}}$ & $\mathrm{S}$ \\
\hline Köfteci üzümü & V. labrusca & $12,0^{\mathrm{f}-\mathrm{i}}$ & $\mathrm{R}$ & $18,7^{\mathrm{h}-\mathrm{k}}$ & $\mathrm{R}$ \\
\hline Mortensen & Interspecific cross & $10,3^{\mathrm{f}-\mathrm{i}}$ & $\mathrm{R}$ & $21^{\mathrm{g}-\mathrm{k}}$ & $\mathrm{R}$ \\
\hline Alden & Interspecific cross & $0^{\mathrm{i}}$ & ER & $15,3^{\mathrm{h}-\mathrm{k}}$ & $\mathrm{S}$ \\
\hline Kay Grey & Interspecific cross & $6,0^{\mathrm{i}}$ & $\mathrm{R}$ & $6,0^{\mathrm{jk}}$ & $\mathrm{R}$ \\
\hline Seneca & Interspecific cross & $57,0^{\mathrm{bc}}$ & HS & $65,3^{b c}$ & HS \\
\hline Canadice & Interspecific cross & $48,0^{\text {cd }}$ & $\mathrm{S}$ & $21^{\mathrm{g}-\mathrm{k}}$ & $\mathrm{R}$ \\
\hline Lakemont & Interspecific cross & $54,0^{\mathrm{c}}$ & HS & $74,6^{\mathrm{ab}}$ & HS \\
\hline
\end{tabular}

a Average severity of powdery mildew across all replicates was rated in 2014 and 2015 for each accession.

${ }^{b}$ Data followed by the same letter in each column do not differ significantly $(\mathrm{p} \leq 0.05)$ according to Duncan's multiple range test. (ER, Extremely resistant; HR, Highly resistant; R, Resistant; S, Susceptible; HS, Highly susceptible)

Each variant was examined using analysis of variance to determine significant differences among accessions. They also were analysed by randomised experimental design analysis of variance with three replicates, also repeated in two years. For each variant, the LS mean differences Student's test (minimum significant difference method) was used to determine the level of resistance for all accessions. Differences at $\mathrm{p}<0.05$ were considered to be significant. All calculations were performed using JMP 7.0 software (SAS Institute, 2007).

\section{RESULTS AND DISCUSSION}

In the study, the resistance level of three different Vitis species or interspecies genotypes to powdery mildew and downy mildew were compared. For downy mildew,
$V$ vinifera cv. Kömüşmemesi showed high sensitivity to both natural infection and artificial inoculation. Some $V$. vinifera varieties, such as Akdimrit, Pembe Gemre and Pembe Üzüm, were the most susceptible cultivars. The varieties most resistant to downy mildew were 53 Güneysu 02 ( V. labrusca) and interspecific cultivars, namely Mortensen, Kay Grey and Canadice (Table 3). The application of artificial inoculation increased the severity of the diseases. Interspecific cultivars and genotypes of $V$. labrusca were found to be more resistant than $V$. vinifera cultivars.

As for downy mildew, artificial inoculation of powdery mildew increased disease severity significantly. $V$. vinifera was the species most affected by powdery mildew, followed by the interspecific cultivars. $V$. labrusca was the most resistant species (Figs 1 and 2; and Table 5). The Giresun 
T-1 and Giresun T-5 genotypes belonging to $V$. labrusca, and the interspecific cultivar Kay Gray, showed the highest resistance. Akdimrit, Antep Büzgülü and Pembe Üzüm (all $V$. vinifera cultivars) were the most susceptible to powdery mildew. These cultivars were more susceptible than Italia, known to be sensitive to powdery mildew (Table 4).

Significant differences were not only found among species, but also among cultivars or genotypes belonging to the same species. These differences are very useful, especially in breeding programmes. Furthermore, cultivars that are very resistant to downy mildew could be very sensitive to powdery mildew, or the opposite situation may apply. For example, $V$. vinifera $\mathrm{cv}$. Kömüşmemesi was found to be very sensitive to downy mildew, while it was resistant to powdery mildew. Similarly, Seneca (an interspecific cultivar) was very sensitive to powdery mildew, but it was quite resistant
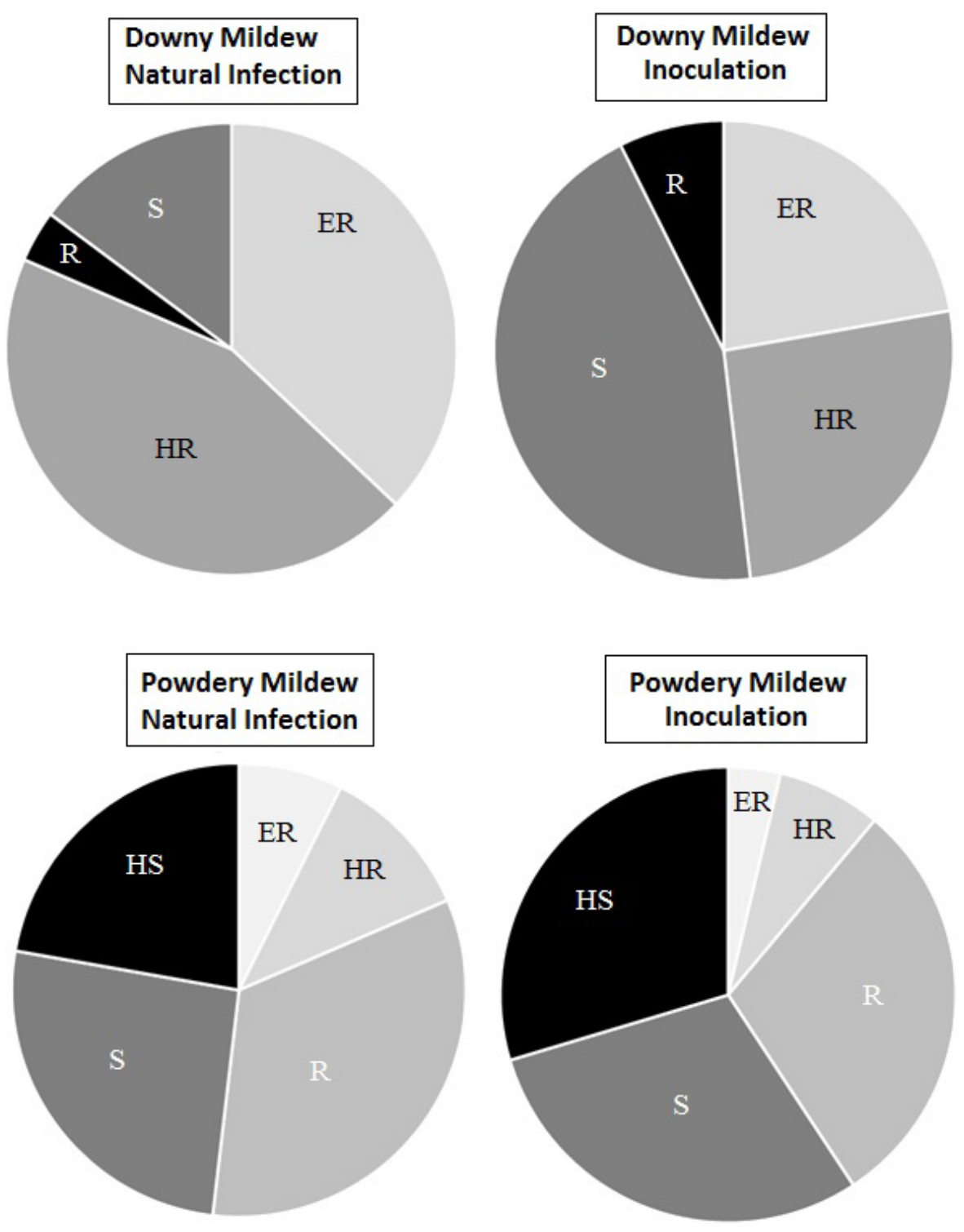

FIGURE 1

Distribution graph based on the number of cultivars by disease severity (ER, Extremely resistant; HR, Highly resistant; R, Resistant; S, Susceptible; HS, Highly susceptible).

TABLE 5

Average disease severity of species

\begin{tabular}{lcccc}
\hline \multirow{2}{*}{ Vitis spp. } & \multicolumn{2}{c}{ DOWNY MILDEW } & \multicolumn{2}{c}{ POWDERY MILDEW } \\
& Natural infection & Inoculation & Natural infection & Inoculation \\
\hline V. vinifera & $27,1^{\mathrm{a}}$ & $44,1^{\mathrm{a}}$ & $32,8^{\mathrm{a}}$ & $48,8^{\mathrm{a}}$ \\
$V$. labrusca & $9,6^{\mathrm{b}}$ & $13,5^{\mathrm{b}}$ & $16,9^{\mathrm{b}}$ & $21,0^{\mathrm{c}}$ \\
Interspecific cross & $2,2^{\mathrm{c}}$ & $4,5^{\mathrm{c}}$ & $29,3^{\mathrm{a}}$ & $33,8^{\mathrm{b}}$ \\
\hline
\end{tabular}


60

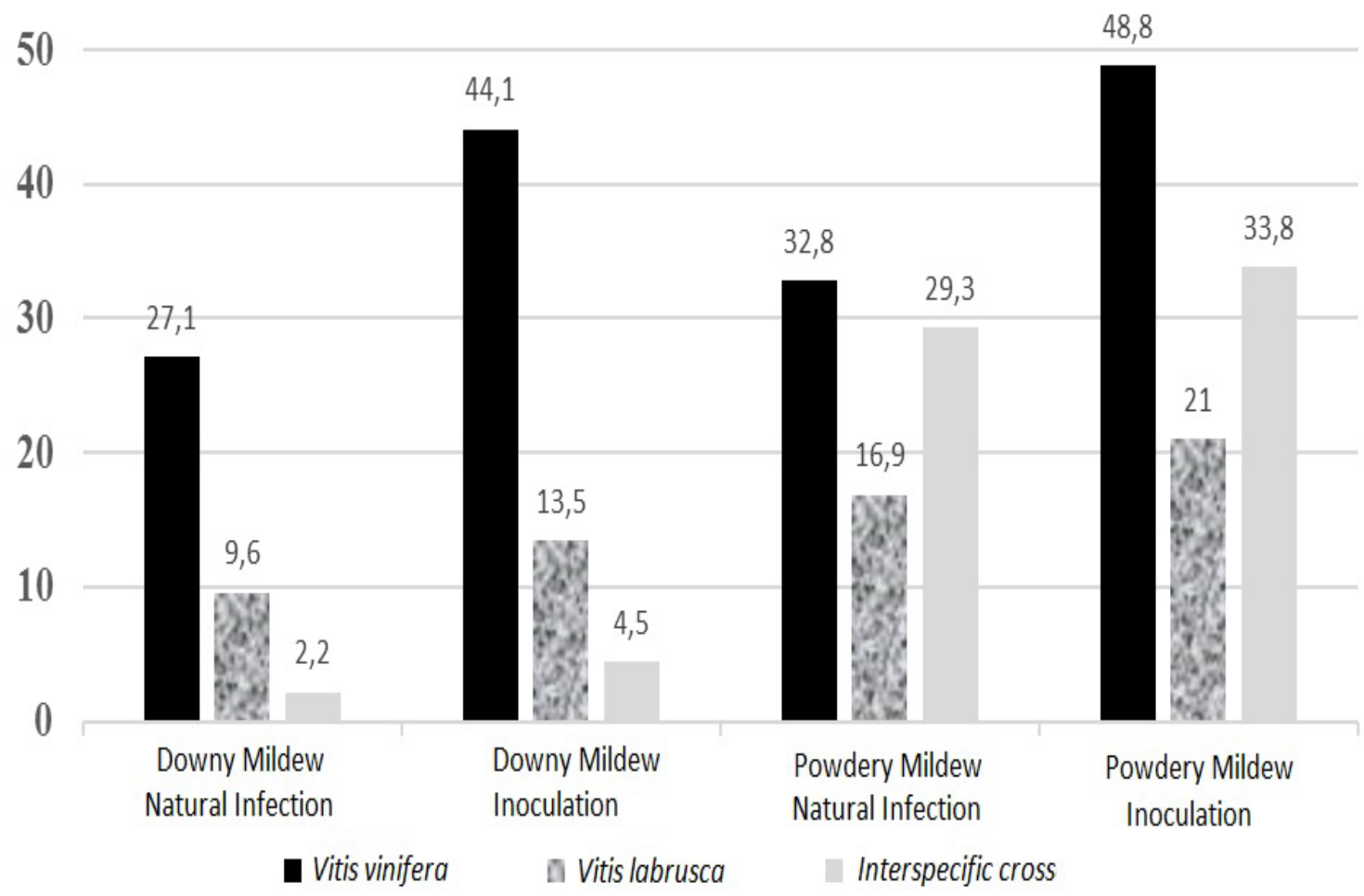

FIGURE 2

Average disease severity graphics of species

to downy mildew. Cadle-Davidson (2008) determined the differences of downy mildew disease severity among leaves of $V$. vinifera, $V$. riparia and $V$. labrusca species and interspecific cultivars. Amongst others, he found differences among cultivars between young and old leaves.

Cadle-Davidson et al. (2011) investigated the resistance level of some Vitis species to different strains of Uncinula necator (syn. Erysiphe necator), the causal agent of powdery mildew. They determined resistance level differences amongst cultivars and also obtained similar results to our study. Furthermore, they also stated that resistance levels in cultivars can differ for different isolates. While species are important in resistance breeding, the resistance level of each cultivar should be determined. It is well known that cultivars belonging to the same species differ in their resistance to pathogens. Similar to the findings in this study, it has been reported that $V$. vinifera cultivars generally have low disease resistance, but it has also been reported that resistance level of cultivars vary.

Gaforio et al. (2015) collected some $V$. vinifera cultivars from different regions of Spain in order to determine their downy mildew resistance. He determined generally high sensitivity of $V$. vinifera cultivars, except for some cultivars collected from the humid regions of Spain. These cultivars showed more resistance than cultivars from other regions. In this study, some $V$. labrusca genotypes grown in the Black Sea region and interspecific cultivars grown in humid regions in the United States were found to have more resistance to downy and powdery mildew than $V$. vinifera cultivars. Cangi et al. (2006) reported that some $V$. labrusca cultivars of American origin are commonly grown in Turkey.

In another study, Lisek (2014) investigated twenty different Vitis cultivars belonging to different species. He reported that interspecific hybrids especially are more resistant to downy and powdery mildew than $V$. vinifera cultivars. He noted that "Muscat Bleu" (of Swiss origin) and "Garant" (of German origin) specifically can be grown in central Poland as resistant cultivars.

In Thailand, due to it having a very favourable climate for fungal diseases, Prajongja et al. (2014) compared the resistance levels of 26 different grape cultivars belonging to different species with different inoculation applications. $V$. vinifera cultivars were especially sensitive, but interspecific hybrids were resistant, similar to the findings of this study. However, they reported some susceptible individuals in interspecific hybrids.

\section{CONCLUSIONS}

In recent years, the protection of human health and safer food production have emerged as very important issues. Using intensive spray applications to control fungal diseases is a big problem in grape production, especially for fresh consumption. Cultivars resistant to fungal diseases must be identified and new breeding programmes must be started to 
increase disease-resistant cultivars of good quality. Recently registered new resistant cultivars need less fungicide spraying and have higher fruit quality. However, the number of commercial cultivars with high resistance to disease and good fruit quality is still very limited. In this study, the resistance levels of some cultivars belonging to different species were determined against two important diseases, namely downy and powdery mildew, under climatic conditions in Yalova. The cultivars with higher disease resistance are intended for use as parents in future breeding programmes.

In recent years, the University of California (Davis), Cornell University (Geneva), USDA-ARS and some European Research Centres have obtained quite promising results. They have identified new gene regions responsible for downy mildew and powdery mildew resistance from wild vines. These newly identified gene regions will help reduce breeding time through the application of molecular markers and provide an important contribution to achieve diseaseresistant/high-quality new varieties.

\section{LITERATURE CITED}

Bailey, L.H., 1934. Gentes Herbarum, Vol. III, Fasc. IV, Article 4, Ithaca, NY, USA.

Boso, S., Martinez, M.C., Unger, S. \& Kassemeyer, H.H., 2006. Evaluation of foliar resistance to downy mildew in different cv. Albariño clones. Vitis 45(1), 23-27.

Cadle-Davidson, L., 2008. Variation within and between Vitis spp. for foliar resistance to the downy mildew pathogen Plasmopara viticola. Plant Dis. $92,1577-1584$

Cadle-Davidson, L., Chicoine, D.R. \& Consolie, N.H., 2011. Variation within and among Vitis spp. for foliar resistance to the powdery mildew pathogen Erysiphe necator. Plant Dis. 95, 202-211.

Cahoon, C.A., 1986. The Concord grapes. Fruit Var. J. 40, 106-107.

Cangi R., Çelik H. \& Köse B., 2006. Determination of ampelographic characters of some natural foxy grape (Vitis labrusca L.) types grown in Northern Turkey (Ordu and Giresun Province). Int. J. Bot. 2, 171-176.

Çelik, H., Köse, B. \& Cangi, R., 2008. Determination of Fox grape genotypes (Vitis labrusca L.) grown in Northeastern Anatolia. Hortic. Sci. (Prague) 35(4), 162-170.

Eibach, R. \& Töpfer, R., 2014. Progress in grapevıne breeding. Acta Hortic. 1046, 197-209.

Gaforio, L., Cabello, F. \& Organero, G.M., 2015. Evaluation of resistance to downy mildew in grape varieties grown in a Spanish collection. Vitis (Special Issue) 54, 187-191.
Gessler, C., Pertot, I. \& Perazzolli, M., 2011. Plasmopara viticola: A review of knowledge on downy mildew of grapevine and effective disease management. Phytopathol. Mediterr. 50, 3-44.

GENRES-081, 1997. Descriptors for grapevines (Vitis spp.). International Union for the Protection of New Varieties of Plants, Geneva, Switzerland / Office International de la Vigne et du Vin, Paris, France / International Plant Genetic Resources Institute, Rome, Italy.

Kozma, P., 1998. Evaluation of fungus resistant wine grape varieties. Acta Hortic. 473, 93-103.

Kozma, P., Hoffmann, S. \& \& Cindric P., 2014. New generation of resistant table grape cultivars. Acta Hortic. 1046, 41-48.

Lisek, J., 2014. Evaluation of yield and healthiness of twenty table grapevine cultivars grown in central Poland. J. Hortic. Res. 22(1), 101-107.

Merdinoglu, D., Blasi, P., Wiedemann-Merdinoglu, S., Mestre, P., Peressotti, E., Poutaraud, A., Prado, E. \& Schneider, C., 2014. Breeding for durable resistance to downy and powdery mildew in grapevine. Acta Hortic. 1046, 65-72.

Mullins, M.G., Bouquet, A. \& Williams, L.E., 1992. Biology of the grapevine. Cambridge University Press, Cambridge, UK.

Özer, C., Solak, E., Öztürk, L. \& Özer, N., 2012. The development of powdery mildew-tolerant grape cultivars with standard quality characteristics by cross breeding. Afr. J. Agric. Res. 7(9), 1374-1380.

Prajongjai, T., Poolsawat, O., Pornbungkerd, P., Wongkaew, S., Tantasawat, P.A., 2013. Evaluation of grapevines for resistance to downy mildew (Plasmopara viticola) under laboratory and field conditions. S. Afr. J. Enol. Vitic. 35, 43-50.

Reisch, B.I., Mahanil, S., Consolie, N., Luce, R.S., Wallace, P.G. \& CadleDavidson, L., 2014. Examination of marker-assisted selection for powdery and downy mildew resistance. Acta Hortic. 1046, 151-155.

Rex, M., Welter, L.J., Töpfer, R. \& Zyprian, E., 2014. Dissecting the genetic determinants of powdery mildew resistance in grape. Acta Hortic. 1046, 79-84.

Rumbolz, J., Wirtz S., Kassemeyer H.H., Guggenheim R., Schäfer E., Büche C., 2002. Sporulation of Plasmopara viticola: differentiation and light regulation. Plant Biol. 4, 413-422.

SAS Institute, 2007. JMP Statistical Discovery Software. JMP 7.0 Edition of programme. SAS Institute Inc., Cary, North Carolina, USA.

Townsend, G.K. \& Heuberger J.W., 1943. Methods for estimating losses caused by diseases in fungicide experiments. Plant Dis. Reptr. 27, 340-343.

Wang, Y., Li, Y., He, P., Chen, J., Lamikanra, O. \& Lu, J., 1995. Evaluation of foliar resistance to Uncinula necator in Chinese wild Vitis species. Vitis $34,159-164$. 